\title{
Bacterial Conjunctivitis and Use of Antibiotics in Dhulikhel Hospital - Kathmandu University Hospital
}

\author{
Sthapit PR, ${ }^{1}$ Tuladhar NR, ${ }^{2}$ Marasini S, ${ }^{1}$ Khoju U, ${ }^{1}$ Thapa ${ }^{1}$
}

\author{
${ }^{1}$ Department of Ophthalmology \\ ${ }^{2}$ Department of Microbiology \\ Dhulikhel Hospital-Kathmandu University Hospital \\ Dhulikhel, Nepal
}

Corresponding Author

Dr Purnima Rajkarnikar Sthapit

Department of Ophthalmology

Dhulikhel Hospital-Kathmandu University Hospital

Dhulikhel, Nepal

E-mail: purnimark@gmail.com

Citation

Sthapit PR, Tuladhar NR, Marasini S, Khoju U, Thapa G. Bacterial conjunctivitis and use of antibiotics in Dhulikhel Hospital - Kathmandu University Hospital. Kathmandu Univ Med J 2011;34(2)69-72.

\begin{abstract}
Background

Acute Infective Conjunctivitis may be due to viral or bacterial infection; though it is usually self limiting, topical antibiotics are often prescribed for rapid recovery.

\section{Objectives}

This study aims to find out prevalence of bacterial infection among cases of acute infective conjunctivitis and to determine their in-vitro antibacterial susceptibilities to commonly used antibacterial agents and to find out whether the rampant use of topical antibiotics are at all necessary or justified.
\end{abstract}

\section{Methods}

A prospective analytical study conducted over a period of two years on clinically diagnosed cases of Acute Infective Conjunctivitis. Isolation and identification of microorganisms by culture and antimicrobial susceptibility test were done on conjunctival swabs from 65 patients.

\section{Results}

A total of 65 patients were included where children (one month to 10 years old) accounted for the commonest age group (35.4\%).On Gram's Stain, 90.8\% were negative for pus cells or micro organisms. Gram positive cocci were found in $6.2 \%$ of cases. On culture, bacterial growth was seen in 11 cases (18.9\%) among which Streptococcus pneumonia was seen in seven cases (10.8\%).The analysis on in-vitro susceptibility testing showed that Chloramphenicol and Gentamicin were the most sensitive ( $78.6 \%$ of samples) drugs for conjunctivitis.

\section{Conclusion}

Ophthalmic antibiotics should be prescribed judiciously in acute infective conjunctivitis even for suspected bacterial cases; since it is found to resolve spontaneously without any serious complications. Chloramphenicol and Gentamicin are drugs of choice if at all required.

\section{Key Words}

acute infective conjunctivitis, bacterial conjunctivitis, chloramphenicol, gentamicin

\section{INTRODUCTION}

Conjunctivitis is the inflammation of the conjunctiva and it is the most frequent cause of red eye. The conjunctivitis may be caused by bacteria, viruses, allergens or irritants. Of these, the acute infective conjunctivitis (AIC) is either the viruses or bacteria.

Bacterial conjunctivitis is relatively less common than viral conjunctivitis. Microbial conjunctivitis is not normally serious and usually moves away spontaneously within a week. However the patients with AIC are often prescribed topical antibiotics as eye drops or ointment for rapid recovery. Prescribing antibiotics for minor self limiting conjunctivitis should be discouraged because of development of antibiotic resistance strain. ${ }^{1}$

The aim of this study is to find out the prevalence of bacterial infection among cases of acute infective conjunctivitis and to determine their in-vitro antibacterial susceptibilities to commonly used antibacterial agents and to find out whether antibiotics therapy is really required or not in all the cases of acute infective conjunctivitis

\section{METHODS}

This is a prospective analytical study carried out at Ophthalmology Department Out Patient Services of Dhulikhel Hospital with 65 patients, of age more than one month old, who presented with a red eye and discharge or "glued eyelids" from Jan 2009 to Dec 2010. History of redness, foreign body sensation, itching and type of discharge were recorded. All the patients were examined 
in slit lamp bio microscope (Topcon) and the presence of congestion, type of discharge, lid edema and corneal superficial punctuate keratitis were noted.

Two sterile broth-moistened cotton swabs were used to collect materials. The swabs were rubbed over the lower fornix of each eye separately, from lateral to the medial side, kept back in sterile test tubes and sent to the laboratory soon after collection.

In the laboratory, on receipt of the swabs, they were seeded on Blood agar and then a smear was made. The smeared slide was stained by Gram stain and Giemsa stain for any evidence of bacteria and the types of inflammatory cells present. The inoculated Blood agar was processed for isolation and identification by standard lab procedure. Antimicrobial susceptibility test of bacterial isolates were done by Kirby Bauer disc diffusion method and interpretation done using National Committee for Clinical Laboratory Standards (NCCLS) serum standards. ${ }^{1}$ Results were tabulated and statistical analysis was performed with Statistical Package for Social Sciences version 11.3(SPSS) program.

\section{RESULTS}

Among 65 patients with red eye and discharge, 60\% of patients were female. Children (one month to 10 years old) (35.4\%) had the highest frequency; followed by $11-20$ years old $(24.6 \%), 21-30$ years old $(20 \%), 31-40$ years old $(9.2 \%)$ and $41-50$ years old (10.2\%).

The symptoms in descending orders were redness of eyes $(89.2 \%)$, swelling of eyes $(69.2 \%)$, watery discharge (52.3\%), discomfort and foreign body sensation (50.8\%), pain (33.8\%), mucoid (29.2\%), mucopurulent (12.3\%) and purulent discharge (1.6\%).

On examination of eyes, $96.8 \%$ had diffuse superficial congestion of conjunctiva, $48.4 \%$ had follicles in lower fornix conjunctiva. Lid edema, matting of lashes and scales were present in $24.2 \%$ of cases. Pseudomembrane was present in $9.7 \%$ of cases and sub conjunctival hemorrhage in $3.2 \%$ of cases. Only one patient had corneal involvement with superficial punctuate keratitis.

On gram staining of the swabs, $90.8 \%$ of samples did not show any pus cells or micro organisms. Gram positive cocci were seen in $6.2 \%$ of samples and rest of the results are tabulated in table 1.

Table 1. Result of Gram stain.

\begin{tabular}{|ll|}
\hline Gram stain & Frequency (\%) \\
\hline No pus cells / No micro organisms & $59(90.8)$ \\
\hline Pus cells only & $5(7.7)$ \\
\hline Gram +ve Cocci & $4(6.2)$ \\
\hline Gram +ve Bacilli & $1(1.5)$ \\
\hline Gram -ve Cocci & $1(1.5)$ \\
\hline Gram -ve Bacilli & $0(0.0)$ \\
\hline
\end{tabular}

Table 2. Result of Blood agar culture.

\begin{tabular}{ll}
\hline Culture & Frequency (\%) \\
\hline MRSA & $2(3.1)$ \\
\hline Morenella catarrhalis & $2(3.1)$ \\
\hline Streptococcus pneumoniae & $7(10.8)$ \\
\hline Staphyloccus aures & $6(9.2)$ \\
\hline No Growth & $54(73.8)$ \\
\hline
\end{tabular}

Growth was seen in 11 cases only (18.9\%)in Blood Agar (table 2), six of them being children of age less than 10 years old. The commonest organism grown was Streptococcus pneumoniae (seven cases, 10.8\%). The analysis on in-vitro susceptibility testing shows that Chloramphenicol and Gentamycin were the most sensitive (78.6\% of samples) as (table 3). Two cases of MRSA were sensitive to Gentamicin Chloramphenicol and Ciprofloxacin.

Table 3. Antibiotic Sensitivity test results.

\begin{tabular}{ll}
\hline Sensitivity & Frequency (\%) \\
\hline Cephalexin & $8(12.3)$ \\
\hline Gentamicin & $11(16.9)$ \\
\hline Chloramphenicol & $11(16.9)$ \\
\hline Ciprofloxacin & $8(12.3)$ \\
\hline Ceftazidine & $1(1.5)$ \\
\hline Cefazoline & $3(4.6)$ \\
\hline Penicillin (P) & $8(12.3)$ \\
\hline Cloxacillin & $4(6.2)$ \\
\hline Norfloxacin & $3(4.6)$ \\
\hline Ofloxacin & $2(3.1)$
\end{tabular}

One way Analysis of Variance (ANOVA) test with Staphylococcus aureus and Streptococcus pneumonia as independent variables and Chloramphenicol, gentamicin and Ciprofloxacin as dependent variable (table 4) revealed significant correlations.

Table 4. One way ANOVA test with the type of bacteria and the antibiotics used.

\begin{tabular}{|lll|} 
Antibiotics & \multicolumn{2}{c}{ P value } \\
& $\begin{array}{l}\text { Staphylococcus } \\
\text { aureus }\end{array}$ & $\begin{array}{l}\text { Streptococcus } \\
\text { pneumoniae }\end{array}$ \\
\hline Chloramphenicol & 0.0001 & 0.002 \\
\hline Ciprofloxacin & 0.0001 & 0.009 \\
\hline Gentamicin & 0.0001 & 0.000 \\
\hline
\end{tabular}

\section{DISCUSSION}

In this two years prospective study in the patients attending the Eye Out Patients services, most of them were children (35.4\%) followed by young adults $(24.6 \%)$ presenting with acute infective conjunctivitis. The principal presenting clinical features were red eyes (89.2\%) and swelling of lids (69.2\%).The age group of patients mostly affected were students indicating that conjunctivitis like all other communicable diseases are due to frequent contact 
with infective organisms either at school or college. One in eight schoolchildren has an episode of acute infective conjunctivitis every year in Canada. ${ }^{2}$

A mucopurulent or purulent discharge is said to be most commonly seen in bacterial or chlamydial conjunctivitis, whereas watery discharge is supposed to be more typical of a viral conjunctivitis. In this study, the findings of pseudomembrane (9.7\%), mucopurulent (12.3\%) and purulent discharge $(1.6 \%)$ proved to be of bacterial in origin only in one tenth of the cases. Presence of follicles in $48.8 \%$ suggests that at least half of the conjunctivitis is of viral in origin. Only one patient had superficial punctuate keratitis and rest of them healed without any complications in our follow up studies indicating that AIC is an innocuous condition. $90.8 \%$ of samples did not show any pus cells or micro organisms in direct Gram stain and Giemsa stain which statistically indicates that most cases of AIC are not bacterial in origin. Among positive results, $7.7 \%$ of samples showed pus cells only. Gram positive cocci were seen in $6.2 \%$ of samples whereas gram positive bacilli and gram negative cocci was seen in $1.5 \%$ of samples. Similar results were reported in a study done in South India where the most frequently isolated bacterial isolates were grampositive cocci $(70 \%)$ followed by gram-negative bacilli (15.85\%) and gram-positive bacilli (10\%). ${ }^{3}$

On Blood agar culture, growth was seen in 11 cases only (18.9\%).No growth was seen in 54 samples $(83.1 \%)$ suggesting again that most of the cases are viral conjunctivitis which does not need antibiotics at all. The commonest organism grown was S. pneumoniae (10.8\% of cases). Everitt $\mathrm{HA}$ detected bacterial growth in $50 \%$ of swabs in patients with conjunctivitis, among which organisms were $\mathrm{H}$. influenzae (26 swabs, 38\%), S.pneumoniae (16 swabs, 23\%), and S. aureus $(11,16 \%) .{ }^{4}$ Other studies done by Steven J. Lichtenstein et al and Greenberg D et al reported similar bacterial isolates. ${ }^{5,6}$

The more culture positives in the above studies most probably are due to sample selection where the patients were children and young adults in whom bacterial infection is more common. In our study also, among 17 culture positives, 10 samples were from patients $<20$ years old. Only seven culture positives were from age group 20-50 years old which suggests that bacterial conjunctivitis is common in younger age group while viral is more common in older age group. Similar results were seen in one study done in adults where bacterial pathogens were present in only $32 \%$ of cases. Further more, bacteria that reside among the normal ocular flora can result in "false positives" when microbiologic tests are performed. ${ }^{2}$

Vichyanond $P$. et al reported excellent sensitivity with Chloramphenicol and Tetracycline against Gram negative and positive bacteria of all age groups. ${ }^{7}$ Another study reported that most of the bacterial isolates were susceptible to Gatifloxacin (650 of 776; 83.76\%) and Ofloxacin (626 of 776; 80.67\%). ${ }^{6}$ In our study Chloramphenicol, Ciprofloxacin and Gentamicin responded to all the bacterial conjunctivitis cases. The two samples had MRSA strain positive which was found during outbreak of MRSA in five wards of our hospital. MRSA are known for their resistance to many systemic antibiotics but in our case they were sensitive to Gentamicinm, Chloramphenicol and Ciprofloxacin and were treated quite easily. Resistance develops rapidly and easily amongst Pseudomonas aeruginosa and other gram-negative rods to Fluoroquinolones, (Ciprofloxacin, Ofloxacin) so these should not be used except in exceptional circumstances when they are indicated. Chloramphenicol is the treatment of choice in New Zealand, Australia and the United Kingdom for uncomplicated conjunctivitis in adults and children. ${ }^{1}$ Chloramphenicol and Gentamicin are most cost effective antibiotics in Nepal and also the ones with least side effect and hence safe to prescribe in children. So from this study we can suggest Chloramphenicol and Gentamicin for AIC if at all indicated especially in children.

Most General Practitioners still prescribe topical antibiotics for most cases of AIC, a condition where only half of the cases are likely to be due to a bacterial infection and even they are self-limiting. ${ }^{8,4}$ A double-blind case control trial in children by $P$. Rose et al and Genevieve $F$ Oliver in two separate studies mentions that placebo and antibiotic had similar cure rates in AIC. ${ }^{1,9,10}$ Kari Lee Visscher et al and Genevieve $\mathrm{F}$ Oliver et al mention that inappropriate treatment of viral conjunctivitis with antibiotics can raise concerns of antibiotic resistance, cost-effectiveness, and potential increase of complications due to antibiotic use. Moreover, treatment of all red eyes with topical antibiotics can result in a delay in diagnosis of other non infective conditions with red eye and watering like iritis and acute angle closure glaucoma, which if not diagnosed and treated on time can lead to serious complications. ${ }^{1,2}$

A qualitative study of patients' perceptions of acute conjunctivitis performed in the UK revealed that most patients when informed about the self limiting nature of the disease were satisfied without antibiotic prescription. ${ }^{1}$ So whenever viral origin is suspected, we can educate the patients regarding its self-limiting nature and side effects of unnecessary prescription of antibiotics.

\section{CONCLUSION}

When a patient with red eye presents, a focused history and ocular examination can make a clinical diagnosis of acute infective conjunctivitis and rule out any red flags that might indicate a different and potentially more serious condition. Routine Gram's stain, culture and sensitivity are not recommended due to low positive yield, cost and time involved in doing so. Even for suspected bacterial cases, ophthalmic antibiotics should be prescribed judiciously and only if there is no improvement after 2 to 3 days of conservative management since it is found to resolve spontaneously without any serious complications. Chloramphenicol and Gentamicin are drugs of choice 
because they have highest sensitivity rate, least side effect, cost effective and safe in children.

\section{REFERENCES}

1. Oliver GF, Wilson GA, Everts RJ. Acute infective conjunctivitis: evidence review and management advice for New Zealand practitioners. Journal of the New Zealand Medical Association 2009; 122(1298):6971.

2. Visscher KL, Hutnik ML C, Thomas M. Evidence-based treatment of acute infective conjunctivitis. Breaking the cycle of antibiotic prescribing. Can Fam Physician 2009;55(11):1071- 5 .

3. Ramesh S, Ramakrishnan R, Bharathi MJ, Amuthan M, Viswanathan S. Prevalence of bacterial pathogens causing ocular infections in South India. Indian J Pathol Microbiol 2010;53:281-6.

4. Everitt HA, Little PS, Smith PW. A randomised controlled trial of management strategies for acute infective conjunctivitis in general practice. BMJ 2006 Aug 12;333(7563):321.

5. Steven J. Lichtenstein -A literature review on Bacterial Conjunctivitis: A Literature Review of the Most Recent Publications on the Subject. BMJ 2006 Aug 12;333(7563):321.

\section{ACKNOWLEDGEMENT}

We would like to thank Mr. Roshan Kumar Mahato (MPH) for his assistance in statistical analysis.

6. Greenberg D, Buznach N, Dagan R. Antibiotic-Resistant Bacterial Conjunctivitis (BC) in Young Children. Interscience Conference on Antimicrobial Agents and Chemotherapy (42nd : 2002 : San Diego, Calif.). Abstr Intersci Conf Antimicrob Agents Chemother Intersci Conf Antimicrob Agents Chemother. 2002 Sep 27-30; 42: abstract no. G-1455. Ben-Gurion Univ, Beer-Sheva, Israel.

7. Vichyanond $P$, Brown $Q$, Jackson $D$. Acute bacterial conjunctivitis. Bacteriology and clinical implications. Clin Pediatr 1986;25(10):506-9.

8. Rietveld R P, Van Weert H C, Ter Riet G. Diagnostic impact of signs and symptoms in acute infectious conjunctivitis: systematic literature search. BMJ 2003;327(7418):789.

9. Rose P. Management strategies for acute infective conjunctivitis in primary care: a systematic review. Expert Opin Pharmacother 2007;8(12):1903-21.

10. Rose P, A.Harnden, A.Brueggemann, R.Perera, A.Sheikh, D.Crook, D.Mant. Chloramphenicol treatment for acute infective conjunctivitis in children in primary care: a randomised double-blind placebocontrolled trial. Lancet 2005;366(9479):37-43. 